\title{
BMJ Open Area-based inequalities and distribution of healthcare resources for managing diabetes in South Korea: a cross- sectional multilevel analysis
}

\author{
Rangkyoung $\mathrm{Ha}$ (D) , ${ }^{1}$ Kyunghee Jung-Choi ${ }^{2}$
}

To cite: Ha R, Jung-Choi K. Area-based inequalities and distribution of healthcare resources for managing diabetes in South Korea: a cross-sectional multilevel analysis. BMJ Open 2022;12:e055360. doi:10.1136/ bmjopen-2021-055360

- Prepublication history for this paper is available online. To view these files, please visit the journal online (http://dx.doi. org/10.1136/bmjopen-2021055360).

Received 09 July 2021 Accepted 28 January 2022

A) Check for updates

(c) Author(s) (or their employer(s)) 2022. Re-use permitted under CC BY-NC. No commercial re-use. See rights and permissions. Published by BMJ.

${ }^{1}$ Department of Health Policy and Management, Seoul National University Graduate School of Public Health, Seoul, Republic of Korea

${ }^{2}$ Department of Occupational and Environmental Medicine, Ewha Women's University College of Medicine and Graduate School of Medicine, Seoul, Republic of Korea

Correspondence to Dr Kyunghee Jung-Choi; jungchoikh@gmail.com

\section{ABSTRACT}

Objectives We aimed to identify area-based socioeconomic inequalities in diabetes management and to examine whether the distribution of healthcare resources could explain area-based inequalities in diabetes management.

Design Cross-sectional multilevel analysis from national survey data.

Setting and participants Data were derived from the 2018 Korean Community Health Survey. Study subjects included 23760 participants aged 30 years or older with diabetes diagnosed by a doctor.

Main outcome measures The dependent variables were self-reported good glycaemic control, haemoglobin $\mathrm{A} 1 \mathrm{c}(\mathrm{HbA1c})$ testing, recognition of the term $\mathrm{HbA1c}$, and diabetic complications testing. Area Deprivation Index was used as an area-based measure of socioeconomic position. Factors related to regional healthcare resources - the coefficient of variation (CV) value of clinics and the number of physicians per 1000-were considered as potential mediating variables in explaining the association between diabetes management and area deprivation. A multilevel logistic regression analysis was used.

Results Compared with the least deprived quintile, the likelihoods of not taking $\mathrm{HbA} 1 \mathrm{c}$ tests, not recognising the term $\mathrm{HbA1c}$, and not taking diabetic complication tests in the most deprived quintile were approximately 1.5 times (95\% Cl 1.25 to 1.80), 2.6 times ( $95 \% \mathrm{Cl} 1.97$ to 3.45 ) and two times ( $95 \% \mathrm{Cl} 1.67$ to 2.48 ) higher, respectively. In the most deprived quintile, CV value of clinics was the highest and the number of doctors was the lowest. Regional healthcare resource factors explained inequalities in managing diabetes by $14 \%-18 \%$, especially in the most deprived quintile.

Conclusions The results in this study suggest that socioeconomic inequalities in diabetes management may be explained by regional healthcare resource disparities. Policy interventions for a more even distribution of healthcare resources would likely reduce the magnitude of regional socioeconomic inequalities in diabetes management.

\section{INTRODUCTION}

Diabetes is one of the major risk factors affecting the poor quality of life and
Strengths and limitations of this study

- We used a multilevel model to identify the inequalities at the area level and to assess the role of potential mediators in explaining the association between diabetes management and the Area Deprivation Index.

- Relatively small administrative districts (median population size about 180000 ) were used to identify area-based inequalities, and information about the number of clinics in smaller units (median population size about 10 thousand) was also used.

- The use of medical institutions could go beyond administrative districts, but this point could not be considered in the present study.

- This is a cross-sectional study, which could not represent a causal relationship.

- We could not use the weighting values in the multilevel analysis, SAS GLIMMIX, which may not guarantee the representativeness of the sample data.

premature death and can lead to a variety of complications, such as heart attacks, stroke, amputation of the lower extremities and impaired vision. ${ }^{12}$ The prevalence of diabetes is increasing worldwide, and in 2019, there were an estimated 463 million people with diabetes worldwide. ${ }^{1}$ The age-standardised prevalence of diabetes has nearly doubled since 1980 , from $4.7 \%$ to $8.5 \%$. $^{2}$

According to Korea Disease Control and Prevention Agency, the age-standardised prevalence of diabetes in Korean adults over the age of 30 has risen from $9.5 \%$ in 2007 to $10.4 \%$ in $2018 .^{3}$ Although early diagnosis and management of diabetes is important, low diabetes management control rates were reported. In 2018, 3-4 out of 10 people with diabetes were not aware they had the disease $(35 \%)$. Around $40 \%$ of people with diabetes were not receiving treatment, and the control rate with a target goal of haemoglobin A1c (HbAlc) $<6.5 \%$ was $28.3 \%{ }^{4}$ 
Studies conducted in other countries have demonstrated inequalities in diabetes management depending on ones' socioeconomic position (SEP). At the individual levels, diabetes patients with lower education and lower income levels were more likely to have poor glycaemic control than those with higher education and income levels. ${ }^{5-7}$ The patients with diabetes with lower SEPs such as education and income used less hospital care than the diabetes patients with higher SEPs. ${ }^{78}$ At the regional level, the deprived areas were positively associated with having less HbAlc testing ${ }^{9}$ and higher HbAlc values ${ }^{10-12}$ in people with diabetes.

Meanwhile, enhancing continuity of care is important in diabetes management, ${ }^{13}$ which may require improved access to regional healthcare services. Accessibility to health services can be classified into different dimensions. ${ }^{14}$ The major barriers to healthcare access are affordability (ie, economic accessibility) and availability (ie, physical accessibility). ${ }^{15}$ Availability is related to the physical distribution of healthcare resources. ${ }^{16}$ Even distribution, along with the appropriate amount of healthcare resources, is required to assure access to healthcare services. ${ }^{17-19}$ However, the healthcare accessibility improvement policy in South Korea has been focused on achieving equality in healthcare expenses through the expansion of insurance benefits over the past few decades, ${ }^{20}$ with few policies prioritising macrolevel healthcare resource allocation.

Furthermore, the healthcare resource supply system in South Korea operates via a market mechanism, so that healthcare resources are distributed in a way that benefits the medical institutions' profits, not service needs..$^{21}{ }^{22}$ As a result, healthcare providers and healthcare institutions, including hospitals and clinics, are concentrated in the big cities, and facilities and healthcare staff are relatively scarce in rural areas. ${ }^{23}$

Inequalities in the regional distribution of healthcare resources may work in the same way for diabetes management. In other words, the regionally disproportionate distribution of healthcare resources could lead to healthcare disadvantages in diabetes care in certain areas. However, most research on diabetes health inequalities in South Korea is about differences in diabetes prevalence depending on individual SEPs. ${ }^{24-26}$ There is limited research on area-based inequalities in diabetes management. Furthermore, there is a lack of research on whether inequalities in the regional distribution of healthcare resources are associated with inequalities in diabetes management. Therefore, our main objectives were to identify the existence of area-based socioeconomic inequalities in diabetes management and to examine whether the distribution of healthcare resources could explain area-based inequalities in diabetes management.

\section{METHODS}

\section{Data and study subjects}

We used the 2018 Korean Community Health Survey (KCHS) conducted by the Korea Disease Control and
Prevention Agency. Data are available on request. ${ }^{27}$ The KCHS is a national health survey including Koreans aged 19 years or older. In order to obtain a sample representing each city $(\mathrm{Si})$, county (Gun), and district $(\mathrm{Gu})$ of the entire Republic of Korea, the stratified probability proportionate sampling method was used. To secure an adequate sample size in each $\mathrm{Si}$, Gun and $\mathrm{Gu}$, if the interviewer could not meet a household member even after three visits to a household, a replacement method of selecting a random other substituted households was used. The completion rate of households was about $94 \%$, and response rate of household members was about $95 \%$ in $2010 .^{28}$

The KCHS collects information on SEP, healthcare utilisation, health behaviours, including smoking, drinking, exercise and weight control, and non-communicable diseases diagnosed by doctors. It is designed as a crosssectional survey and is carried out annually using Computer Assisted Personal Interviewing. A trained interviewer visits the sampled household and conducts a one-on-one interview. Responses to the KCHS are made with the consent of the participant and can be withdrawn according to the KCHS questionnaire protocols. More information about the KCHS is available elsewhere. ${ }^{29}$

Among a total of 228340 participants in 2018, our study was limited to 25396 respondents who were diagnosed with diabetes by a physician. Participants with any missing data were excluded. Because the prevalence of diabetes in people aged under 30 was relatively very low $(<1 \%)^{30}$ and the number of people under the age of 30 who responded that they had diabetes was actually very small (69 people), participants under 30 years of age were excluded from the study. Our final analysis included 23 760 participants aged 30 or older (see figure 1 ).

To identify local-level healthcare resources, we also used data on the current status of primary care clinics in 2018 and the number of doctors affiliated with a medical institution at $\mathrm{Si}$, Gun and Gu levels. This data are provided by the Health Insurance Review and Assessment Service,

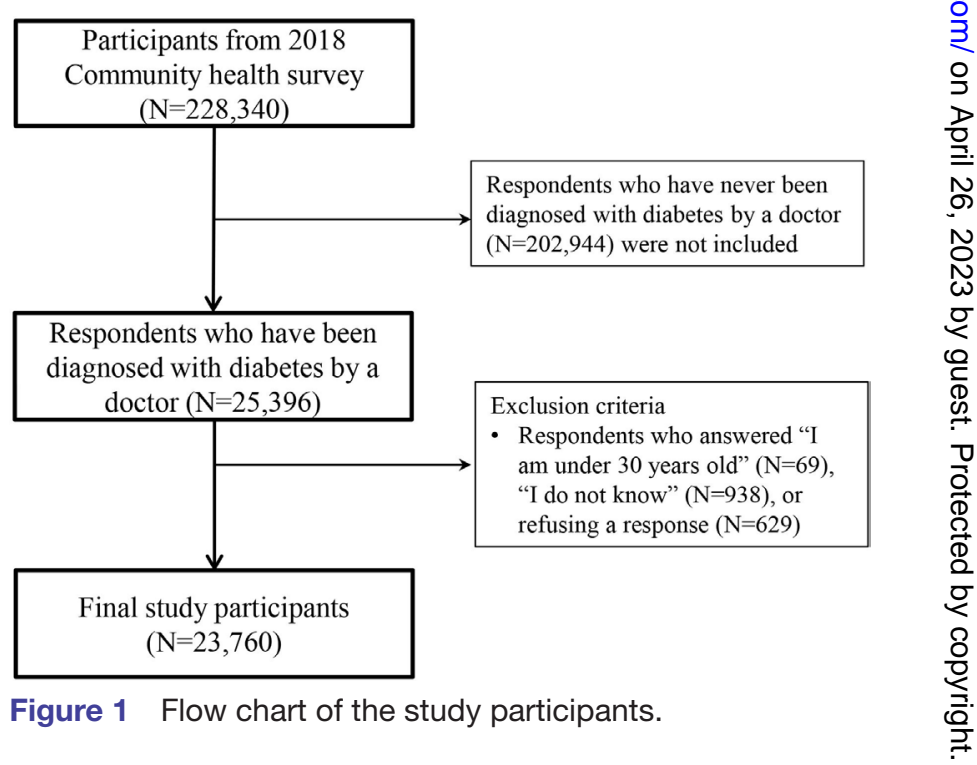

Ha R, Jung-Choi K. BMJ Open 2022;12:e055360. doi:10.1136/bmjopen-2021-055360 
which manages healthcare resources including human resources for healthcare, health facilities and medical equipment in South Korea. These data are openly available at the Public Data Portal. ${ }^{31}$

\section{Study variables}

We used indicators related to managing diabetes as dependent variables, such as: (1) self-reported good glycaemic control, (2) HbAlc testing, (3) recognition of the term HbAlc and (4) diabetic complications testing. Self-reported good glycaemic control was defined as cases answering 'yes' to the question 'Is your blood glucose under control?' among those who used insulin injections or oral hypoglycemic agents to manage their diabetes. HbAlc testing was defined as when HbAlc tests were taken at least twice in the last year per Korean Diabetes Association recommendations. ${ }^{32}$ Recognition of the term HbA1c was measured using the question 'How many HbA1c tests have you taken in the past year?' Respondents who answered 'More than four times, three times, two times, one time or never' were defined as those who knew what an HbAlc test is. Respondents who answered 'I do not know what an HbAlc test is' were defined as those who did not. Diabetic complication testing was measured using the questions 'Have you had a fundus examination in the past year to see if there have been any complications in your eyes caused by diabetes? and 'Have you taken a test for microalbuminuria to see if you have developed kidney complications due to diabetes?' Respondents who answered 'Yes, I have' to either of these two questions were considered to have had complication testing.

The Area Deprivation Index is a composite measure of material and social deprivation levels of regions. ${ }^{33}$ It was used as an area-based measure of SEP in the present study. The existing calculated area deprivation index was used in this study. ${ }^{34}$ The Area Deprivation Index was calculated in a South Korean context using the 2015 Population and Housing Census data in Korea. Statistics Korea carries out a Population and Housing Census every 5 years to identify all Koreans and foreigners residing in South Korea and to assess size and characteristics of housing. ${ }^{36}$ It was calculated using the proportion of those of a low social class, in poor housing conditions, with a low education level, divorced or bereaving, people living alone, in a female-headed household, the elderly, households without a vehicle, and households not living in an apartment. Each of these nine variables was standardised using a Z-score, then combined to compute the area deprivation index. ${ }^{34}$ The area deprivation index was classified into quintiles, with lower area deprivation index values $(\mathrm{Q} 1)$ representing less deprivation.

We used sociodemographic factors, individual SEP and health behaviour-related factors to determine the neighbourhood compositional effects. Sociodemographic variables included gender, age, marital status. Marital status was categorised as currently married, never married or previously married. Individual-level SEP indicators were educational level, household income, occupation, receipt of National Basic Livelihood Security benefits, and residential area. Educational level was classified as elementary school or less, junior high school graduate, high school graduate or college graduate or higher. Equivalised household income (represented in quartiles) was calculated by dividing the total monthly household income by the square root of the total household members. Occupations were divided into professional/clerical, service/ sales, manual, homemaker, unemployed, and other, which included soldiers and students. Receipt of National Basic Livelihood Security benefits was dichotomised as yes or no. The regions were classified into metropolitan, urban and rural areas.

Health behaviour-related variables consisted of smoking, drinking and regular physical activity. Smoking was dichotomised as yes (current smoker) or no (former smoker or never a smoker). Drinking alcohol was also dichotomised as yes (drinkers who have drunk for the past year) or no (never a drinker or drinkers who has not consumed alcohol for the past year). ${ }^{37}$ Regular physical activity was defined as walking for more than $30 \mathrm{~min}$ a day on more than 5 days a week, based on guidelines for the Practices of Physical Activities for the Prevention of Cancer in South Korea. ${ }^{38}$

Factors related to regional healthcare resources included a coefficient of variation (CV) and the number of physicians per 1000 population to identify contextual neighbourhood effects. CVs of clinics was used to identify how evenly clinics were distributed in each of the 250 districts. The formula of the $\mathrm{CV}$ is $(\mathrm{SD} /$ mean $) \times 100$. The $\mathrm{CV}$ of clinics in each district was calculated using SD and the mean of the number of clinics in Dong/Eup, Myeon (median population size about 10 thousand), which are subadministrative units under $\mathrm{Si}$, Gun, and $\mathrm{Gu}$ districts (median population size about 180000 ). If clinics are distributed in a balanced way through Dong/Eup, Myeon in a relevant $\mathrm{Si}$, Gun, or $\mathrm{Gu}$ district, then the $\mathrm{CV}$ value decreases, and if clinics are concentrated in some Dong/ Eup, Myeon, then the CV value increases. That means high $\mathrm{CV}$ values represent a large deviation in the number of clinics. The number of physicians per 1000 population was defined as physician density, which is the number of medical doctors, including generalists and specialists, relative to a district's population. We presented the CV value and the number of physicians per 1000 population as mean, $\mathrm{SD}$, and percentage above a certain standard; the median value for $\mathrm{CV}$ and the Organisation for Economic Co-operation and Development (OECD) average for the number of physicians per 1000 population in South Korea. $^{39}$

\section{Statistical analysis}

We calculated frequencies and the weighted proportion of socio-demographic and health behaviour-related variables by gender to identify the study population's distribution. Age-standardised rates of managing diabetes were also calculated according to study participant characteristics. 
We used a multilevel logistic regression analysis to analyse the hierarchical data. ${ }^{40}$ For the multilevel analyses, we included regions as a random intercept and built four models to estimate fixed effects. A multilevel model was constructed to examine the association between diabetes management and area deprivation. We created a baseline model and three additional models to assess the role of potential mediating variables in explaining the association between diabetes management and the Area Deprivation Index. This was intended to determine how the distribution of regional healthcare resources explains the inequality in diabetes management. We included gender, age and the Area Deprivation Index in a baseline model (model 1). Model 2 included healthcare resource variables (ie, CV and the number of physicians per 1000 population) additional to model 1 . In model 3, individual SEP indicators and health behaviour-related variables were added to model 1 . Model 4 included all of the study variables.

The explanatory power of potential mediating variables was represented by the percentage change in the OR by adding potential mediating variables to a baseline model. This method has been used to assess the contribution of potential mediating variables towards socioeconomic inequality in health. ${ }^{41-46}$ The explanatory power is calculated as $100 \times[($ OR in model 1$)-($ OR in the model adjusted for potential mediating variables $)] /[(\mathrm{OR}$ in model 1)]. All statistical analyses were performed using the SAS GLIMMIX procedure (PROC GLIMMIX, SAS V.9.4, SAS Institute). Our analyses using PROC GLIMMIX, which cannot allow for survey weights may not guarantee the representativeness of the sample data.

\section{Patients and public involvement}

Patients and/or the public were not involved in the design, or conduct, or reporting, or dissemination plans of this research.

\section{RESULTS}

The general characteristics of the study population are shown in table 1 . There were 23760 people who had been diagnosed with diabetes: 11496 (48.4\%) males and $12264(51.6 \%)$ females. The proportion of those aged $70-79$ years was higher $(31.9 \%)$, followed by those aged $60-69$ years $(30.4 \%)$. The proportions of people with an elementary school education or lower $(46.5 \%)$ and high school graduates $(24.5 \%)$ were higher, compared with junior high school graduates $(16.4 \%)$ and those with a college degree or higher (12.6\%). Among women who had been diagnosed with diabetes, those with an elementary school education or lower tended to have a higher proportion $(64.0 \%)$. Manual workers tended to have a higher proportion $(32.7 \%)$, followed by unemployed people $(27.0 \%)$, homemakers $(24.9 \%)$, service workers $(8.4 \%)$, and professional workers $(6.9 \%)$. However, among women, homemakers had the highest proportion $(47.9 \%)$ of having been diagnosed with diabetes. The proportions were high for those within married people $(69.8 \%)$ and those who were not recipients of National Basic Livelihood Security benefits (93.6\%).

Table 2 describes the age-standardised rates of managing diabetes. Among study subjects, the age-standardised rate of self-reported good glycaemic control was $76.3 \%$, the rate of HbAlc testing was $41.0 \%$, that of recognition of the term HbA1c was $82.6 \%$, and that of diabetic complication testing was $30.6 \%$. The rates of self-reported good glycaemic control and $\mathrm{HbAlc}$ testing were higher in men than in women, while the rates of recognising the term Hb1Ac and diabetic complication testing were similar in men and women. All four diabetes management rates were higher in those with a spouse. The rate of self-reported good glycaemic control was $77.2 \%$ for those with a college degree or higher and $79.2 \%$ for those with an elementary school education or lower, with a gap of $-2 \%$ points. The difference between the two groups in diabetic complications testing accounted for $-3.4 \%$ points. In contrast, the differences in HbAlc testing and recognition of the term Hb1Ac were $18.6 \%$ points and $21.4 \%$ points, respectively.

For household income level, the rates of diabetes management were highest in the fourth quartile, with the difference between the group in the first quartile being $4.5 \%$ points, $8.8 \%$ points, $16 \%$ points and $6.6 \%$ points, respectively. The household income level in this study means the first quartile was the lowest and the fourth quartile was the highest. Professional people tended to take more HbA1c and diabetic complications tests, had greater awareness of the term HbAlc, and had less selfreported good glycaemic control than the other groups. Those who were not eligible for National Basic Livelihood Security benefits were more likely to have self-reported good glycaemic control, take HbAlc tests and recognise the term HbAlc than recipients, while the rates of complication testing showed the opposite result. For residential areas, the four diabetes management rates were highest in metropolitan areas.

Table 3 presents the distribution of diabetes management rates by area deprivation. There was no clear difference in the rates of self-reported good glycaemic control according to area deprivation, whereas the rates of HbAlc testing in the least and most deprived areas were $39.4 \%$, and $27.3 \%$, respectively. The difference between the two groups was $12 \%$ points. Regarding recognition of the term HbAlc, the rates ranged from $81.8 \%$ in the first quintile (least deprived) to $59.4 \%$ in the fifth quintile (most deprived). The observed difference between the least and the most deprived area was $22.4 \%$ points. The gap between the two groups was $13.8 \%$ points in diabetic complications testing rates.

Table 4 shows the distribution of healthcare resources rates by area deprivation. The $\mathrm{CV}$ value was highest in the most deprived areas, suggesting that clinics were further and more dispersed in districts with poorer socioeconomic conditions. The number of doctors per $1000 \mathrm{popu}-$ lation was 1.4 , which was the lowest in the fifth quintile (most deprived). 
Table 1 Characteristics of the study subjects

\begin{tabular}{|c|c|c|c|}
\hline \multirow[b]{2}{*}{ Variables } & \multirow[b]{2}{*}{ Total $(\mathrm{N}=23 \mathrm{760})$} & \multirow{2}{*}{$\begin{array}{l}\mathrm{N}(\%) \\
\text { Men }(\mathrm{N}=11496)\end{array}$} & \multirow[b]{2}{*}{ Women ( $\mathrm{N}=12$ 264) } \\
\hline & & & \\
\hline \multicolumn{4}{|l|}{ Gender } \\
\hline Women & $12264(51.6)$ & & \\
\hline \multicolumn{4}{|l|}{ Age (years) } \\
\hline $40-49$ & $1446(6.1)$ & $941(8.2)$ & $505(4.1)$ \\
\hline $50-59$ & $4186(17.6)$ & $2382(20.7)$ & $1804(14.7)$ \\
\hline $60-69$ & $7221(30.4)$ & $3720(32.4)$ & $3501(28.6)$ \\
\hline 70-79 & 7575 (31.9) & $3214(28.0)$ & $4361(35.6)$ \\
\hline $80-89$ & $2805(11.8)$ & $983(8.6)$ & $1822(14.9)$ \\
\hline Never married & $579(2.4)$ & $437(3.8)$ & $142(1.2)$ \\
\hline Previously married & $6601(27.8)$ & $1455(12.7)$ & $5146(42.0)$ \\
\hline \multicolumn{4}{|l|}{ Education } \\
\hline$\leq$ Elementary school & $11058(46.5)$ & 3209 (27.9) & $7849(64.0)$ \\
\hline Junior high school graduate & $3896(16.4)$ & $2145(18.7)$ & $1751(14.3)$ \\
\hline High school graduate & $5821(24.5)$ & 3831 (33.3) & $1990(16.2)$ \\
\hline$\geq$ college & $2985(12.6)$ & $2311(20.1)$ & $674(5.5)$ \\
\hline \multicolumn{4}{|l|}{ Equivalised household income* } \\
\hline Service/sales & 1991 (8.4) & 865 (7.5) & $1126(9.2)$ \\
\hline Manual & $7763(32.7)$ & $4837(42.1)$ & 2926 (23.9) \\
\hline Homemaker & $5911(24.9)$ & $33(0.3)$ & $5878(47.9)$ \\
\hline Unemployed & $6422(27.0)$ & $4420(38.5)$ & $2002(16.3)$ \\
\hline Others & $25(0.1)$ & $23(0.2)$ & $2(0.0)$ \\
\hline \multicolumn{4}{|c|}{ Receipt of National Basic Livelihood Security benefits } \\
\hline Yes & $1514(6.4)$ & $597(5.2)$ & $917(7.5)$ \\
\hline No & 22246 (93.6) & $10899(94.8)$ & $11347(92.5)$ \\
\hline \multicolumn{4}{|l|}{ Residential area } \\
\hline Metropolitan & $6205(26.1)$ & $3105(27.0)$ & $3100(25.3)$ \\
\hline Urban & $8635(36.3)$ & $4242(36.9)$ & $4393(35.8)$ \\
\hline Rural & 8920 (37.5) & 4149 (36.1) & 4771 (38.9) \\
\hline \multicolumn{4}{|l|}{ Smoker } \\
\hline Yes & $3676(15.5)$ & $3298(28.7)$ & $378(3.1)$ \\
\hline No & $20084(84.5)$ & 8198 (71.3) & $11886(96.9)$ \\
\hline \multicolumn{4}{|l|}{ Drinker } \\
\hline Yes & 12289 (51.7) & 7730 (67.2) & 4559 (37.2) \\
\hline
\end{tabular}


Table 1 Continued

\begin{tabular}{llll}
\hline & & $\mathbf{N}(\%)$ & \\
\cline { 3 - 4 } Variables & Total (N=23 760) & Men (N=11 496) & Women (N=12 264) \\
\hline No & $11471(48.3)$ & $3766(32.8)$ & $7705(62.8)$ \\
Regular physical activity & & & \\
Yes & $4659(19.6)$ & $2128(18.5)$ & $2531(20.6)$ \\
No & $19101(80.4)$ & $9368(81.5)$ & $9733(79.4)$ \\
\hline
\end{tabular}

*The lowest (Q1) and the highest (Q4).

Table 5 shows the association between poor diabetes management and area deprivation, including the explanatory power of potential mediating variables. In model 1 , there was no association between self-reported good glycaemic control and the area deprivation index. There was a statistically significant likelihood of other diabetes management indicators, especially in more deprived quintiles. The odds of not taking HbAlc tests were greater in the most deprived quintile compared with in the least deprived quintile (OR: $1.50,95 \%$ CI: 1.25 to 1.80 ). The odds of not recognising the term HbAlc were statistically significant in the fifth quintile compared with the first quintile (OR: 2.61, 95\% CI: 1.97 to 3.45 ). The area deprivation index was also significantly associated with not taking diabetic complication tests (OR: 2.04, 95\% CI: 1.67 to 2.48 ).

The explanatory power of individual-level variables in diabetes management was relatively high, while the explanatory power of healthcare resources was substantial. For HbAlc testing, $16.8 \%$ (the fifth quintile) of change was due to healthcare resource factors in model 2. For recognition of the term HbAlc, the percentage changes due to healthcare resources were around $11 \%$ in the fourth quintile and $18 \%$ in the fifth quintile. Healthcare resources explained roughly $14 \%$ of the excess ORs of no diabetic complications testing in the fourth and fifth quintiles. In model 4, which included both regional healthcare resource factors and individual-level variables, the explanatory powers in explaining the association between area deprivation and poor diabetes management, such as recognition of the term $\mathrm{HbAlc}$ and diabetic complications testing, in the most deprived quintile were $58.9 \%$ and $41.0 \%$, respectively.

\section{DISCUSSION}

This study identified area-based inequalities in diabetes management and the extent to which the distribution of healthcare resources could explain such inequalities.

Diabetes management indicators, excluding selfreported good glycaemic control, differed depending on the area deprivation index, especially in more deprived quintiles. People living in the most deprived quintile were approximately 1.5 times less likely to be taking HbAlc tests than those living in the least deprived quintile. Compared with the least deprived quintile, the likelihood of not recognising the term HbAlc and not taking diabetic complication tests in the most deprived quintile were roughly 2.6 times and two times higher, respectively.

Our results were somewhat consistent with previous studies. When using household income, education, occupation and home value as the area-level SEP, people living in the most deprived areas were less likely to receive HbA1c tests and eye examinations. ${ }^{9}$ Also, several studies using the Townsend score or the index of Multiple Deprivation to calculate area deprivation found that those living in the most deprived areas were less likely to get HbAlc testing ${ }^{47}$ and retinopathy, ${ }^{47}$ and had higher HbA1c values than those in the least deprived areas. ${ }^{1248-50}$ This suggests that the most deprived areas have the worst diabetes management.

These area-based inequalities in diabetes management were explained partially by the distribution of healthcare resources. The explanatory power of healthcare resources in explaining the relationship between area deprivation and poor diabetes management was about $17 \%$ in $\mathrm{HbAlc}$ testing, $18 \%$ in recognition of the term $\mathrm{HbA1c}$, and $14 \%$ in diabetic complications testing, especially in the fifth quintile. These results can be explained by the contextual effects of area-based socioeconomic environment. ${ }^{51} 52$ Prior studies showed household income at the community level to be associated with access to healthcare ${ }^{53}$ and with breast and cervical cancer screening, ${ }^{54}$ implying that the relationship went beyond the compositional effects of individuals living in those areas. Disadvantaged neighbourhoods were negatively associated with receiving blood pressure (a $28 \%$ decline in the odds) and cholesterol screening (an 18\% decline in the odds), ${ }^{17}$ compared with a $42 \%$ decline in the odds of HbA1c testing in our study. Uptake of eye examinations for diabetes was lower in more deprived areas, ${ }^{55}$ suggesting patients with poor diabetes management may have an increased risk of developing diabetes complications. According to a previous Korean study, patients with diabetes in more deprived areas had higher hospital admissions related to diabetes complications than those living in less deprived areas. ${ }^{56}$ This indicates that the characteristics of socioeconomically disadvantaged areas affect the ability of individuals to use healthcare services, regardless of their SEP.

People in more deprived areas with greater need have limited access to high-quality healthcare. ${ }^{57}$ Previous 
Table 2 Age-standardised rates of managing diabetes

\begin{tabular}{|c|c|c|c|c|}
\hline \multirow[b]{2}{*}{ Variables } & N (age-standardised \%) & \multirow[b]{2}{*}{ HbA1c testing } & \multirow[b]{2}{*}{$\begin{array}{l}\text { Recognition of the term } \\
\text { HbA1c }\end{array}$} & \multirow{2}{*}{$\begin{array}{l}\text { Diabetic } \\
\text { complications } \\
\text { testing }\end{array}$} \\
\hline & $\begin{array}{l}\text { Self-reported good glycaemic } \\
\text { control }\end{array}$ & & & \\
\hline \multicolumn{5}{|l|}{ Gender } \\
\hline Men & 9535 (79.5) & 3995 (42.6) & 8484 (83.3) & 3295 (30.8) \\
\hline Currently married & $13760(77.1)$ & $5816(42.1)$ & 12120 (84.3) & $4886(31.1)$ \\
\hline Never married & 419 (71.2) & $228(37.9)$ & $460(81.6)$ & $156(29.3)$ \\
\hline Previously married & $5333(70.9)$ & 1610 (39.0) & $3726(77.5)$ & 1627 (29.2) \\
\hline \multicolumn{5}{|l|}{ Education } \\
\hline High school graduate & $4780(76.6)$ & $2381(40.8)$ & $4785(84.5)$ & $1815(30.7)$ \\
\hline$\geq$ College & 2409 (77.2) & $1390(48.1)$ & 2668 (91.2) & 1057 (35.6) \\
\hline \multicolumn{5}{|c|}{ Equivalised household income* } \\
\hline 1st quartile & $4992(74.0)$ & 1367 (35.3) & $3222(71.5)$ & $1328(26.6)$ \\
\hline 2nd quartile & $4522(71.3)$ & $1615(35.8)$ & $3580(80.3)$ & $1556(32.0)$ \\
\hline 3rd quartile & $4892(75.5)$ & $2112(41.6)$ & 4395 (82.6) & $1789(29.5)$ \\
\hline 4th quartile & $5106(78.5)$ & $2560(44.1)$ & 5109 (87.5) & 1996 (33.2) \\
\hline \multicolumn{5}{|l|}{ Occupation } \\
\hline Professional/clerical & $1357(80.5)$ & $773(47.4)$ & 1470 (89.9) & $566(38.4)$ \\
\hline \multicolumn{5}{|c|}{ Receipt of National Basic Livelihood Security benefits } \\
\hline Yes & $1154(69.3)$ & $349(27.9)$ & $878(73.2)$ & $408(32.5)$ \\
\hline No & $18358(76.7)$ & $7305(41.8)$ & 15428 (83.2) & $6261(30.5)$ \\
\hline \multicolumn{5}{|l|}{ Residential area } \\
\hline Metropolitan & $5080(77.2)$ & $2259(42.1)$ & 4788 (85.9) & $2073(32.1)$ \\
\hline Urban & $7071(75.6)$ & $2987(41.0)$ & $6277(82.0)$ & $2605(30.7)$ \\
\hline Rural & $7361(76.2)$ & 2408 (36.3) & $5241(71.2)$ & $1991(22.6)$ \\
\hline \multicolumn{5}{|l|}{ Smoker } \\
\hline Yes & 2946 (78.3) & $1,31(40.8)$ & $2697(80.5)$ & $914(28.1)$ \\
\hline No & $16566(74.6)$ & $6337(40.7)$ & 13609 (83.5) & 5755 (31.3) \\
\hline \multicolumn{5}{|l|}{ Drinker } \\
\hline Yes & 9988 (77.2) & $4427(42.1)$ & $9033(83.0)$ & $3374(29.4)$ \\
\hline No & 9524 (73.6) & 3227 (38.4) & 7273 (81.7) & 3295 (33.7) \\
\hline \multicolumn{5}{|l|}{ Regular physical activity } \\
\hline Yes & 3890 (77.9) & 1566 (41.9) & 3305 (84.5) & 1452 (33.5) \\
\hline No & 15622 (75.9) & $6088(40.8)$ & 13001 (82.1) & 5217 (29.9) \\
\hline
\end{tabular}

${ }^{*}$ The lowest (Q1) and the highest (Q4). $\mathrm{HbA1c}$, haemoglobin A1c. 
Table 3 The distribution of diabetes management rates by area deprivation

(\%)

\begin{tabular}{lllll}
\cline { 2 - 5 } Area deprivation & $\begin{array}{l}\text { Self-reported good } \\
\text { glycaemic control }\end{array}$ & HbA1c testing & $\begin{array}{l}\text { Recognition of the term } \\
\text { HbA1c }\end{array}$ & $\begin{array}{l}\text { Diabetic complications } \\
\text { testing }\end{array}$ \\
\hline 1st quintile & 80.7 & 39.4 & 81.8 & 34 \\
2nd quintile & 81.2 & 37.8 & 77.8 & 34.3 \\
3rd quintile & 80.6 & 35 & 76.3 & 32.9 \\
4th quintile & 81.4 & 34.7 & 69.5 & 26.8 \\
\hline 5th quintile & 82.5 & 27.3 & 59.4 & 20.2 \\
\hline Difference* & -1.8 & 12 & 22.4 & 13.8 \\
\hline
\end{tabular}

The least-deprived (Q1) and the most-deprived (Q5).

${ }^{*}$ Difference between the least and the most deprived area (\% points). $\mathrm{HbA1c}$, haemoglobin A1c.

Korean studies found that a lot of healthcare resources were distributed in cities with high financial independence and high local taxes. ${ }^{58}$ Healthcare resources were distributed by area-based SEP, unrelated to health needs. ${ }^{59}$ When defining geographical accessibility of healthcare resources as the distance between the patient's residence and healthcare institutions visited by the patient, people with diabetes living in rural areas travelled far to visit healthcare institutions compared with their metropolitan and urban counterparts. ${ }^{60}$ This suggests that rural areas have less accessibility to healthcare for managing diabetes than large cities. According to a prior Chinese study that analysed the relationship between the distribution of healthcare resources and diabetes management, an increase in the number of physicians in hospitals and primary health centres was positively associated with visits from patients with diabetes. Especially in rural and less economically developed areas, there was a positive relationship between an increased number of

Table 4 The distribution of healthcare resource rates by area deprivation

\begin{tabular}{llllll}
\hline & & \multicolumn{3}{c}{$\begin{array}{l}\text { The no of } \\
\text { physicians per 1000 } \\
\text { population }\end{array}$} \\
\cline { 2 - 3 } \cline { 5 - 6 } $\begin{array}{l}\text { Area } \\
\text { deprivation }\end{array}$ & Mean \pm SD & $\%^{*}$ & & Mean \pm SD & $\% \dagger$ \\
\hline 1st quintile & $143.16 \pm 58.03$ & 26.0 & $1.58 \pm 1.13$ & 10.0 \\
\hline 2nd quintile & $151.45 \pm 59.33$ & 28.0 & $1.68 \pm 0.63$ & 14.0 \\
\hline 3rd quintile & $184.58 \pm 77.44$ & 50.0 & $1.71 \pm 1.34$ & 14.0 \\
\hline 4th quintile & $200.07 \pm 74.68$ & 58.0 & $1.80 \pm 2.06$ & 12.0 \\
\hline 5th quintile & $227.94 \pm 71.20$ & 72.0 & $1.35 \pm 0.51$ & 2.0 \\
\hline
\end{tabular}

The least-deprived (Q1) and the most-deprived (Q5).

*The percentage of CV values greater than 178.74 (the median of CV).

†The percentage of number of physicians per 1000 population greater than 2.3 (according to OECD standards, the number of physicians per 1000 population in South Korea is 2.3). $\mathrm{CV}$, coefficient of variation; OECD, Organisation for Economic Cooperation and Development. healthcare workers at primary health centres and visits among patients with diabetes, ${ }^{18}$ implying that healthcare resources for better diabetes management need to be allocated more to disadvantaged areas.

Patients with individual low SEPs were likely to have poor diabetes management. This showed that compositional effects have an impact on inequalities in diabetes management by area deprivation, in addition to the aforementioned contextual effects. ${ }^{61}$ This may explain differences in the use of healthcare services and glycaemic control capacity, which may be influenced by the characteristics of the individual (eg, education and income level). Several studies have found low SEPs to be associated with a greater likelihood of having higher HbAlc levels ${ }^{62}$ and a smaller likelihood of receiving eye examinations for diabetes than high SEPs. ${ }^{6}{ }^{63}$ Also, there was an inverse association between diabetes knowledge and glycaemic control among low-income patients with diabetes. ${ }^{65}$

Individual high SEPs could lead to high health literacy, which affects use of healthcare services and glycaemic control capacity. Health literacy refers to the ability of an individual to access, understand and use information in a way that promotes and maintains good health for themselves, their families and their communities. ${ }^{66}$ However, this ability may also be associated with the area-based socioeconomic level. A previous study identified that lower health literacy was significantly associated with higher area deprivation. ${ }^{67}$ Low community-level health literacy contributes to the spread of misconceptions and greater distrust of doctors and of the health system. Differences in area-based health literacy may ultimately affect health outcomes and health inequalities. ${ }^{68-70}$ To reduce areabased health inequalities, the physical environment must be improved and infrastructure established that provides community-wide diabetes management information.

Our study has limitations. First, we performed a crosssectional analysis, which does not represent a causal relationship. Second, we used the distribution of clinics across 250 districts as the indicator of the accessibility of healthcare services. As the use of healthcare services cannot be limited 


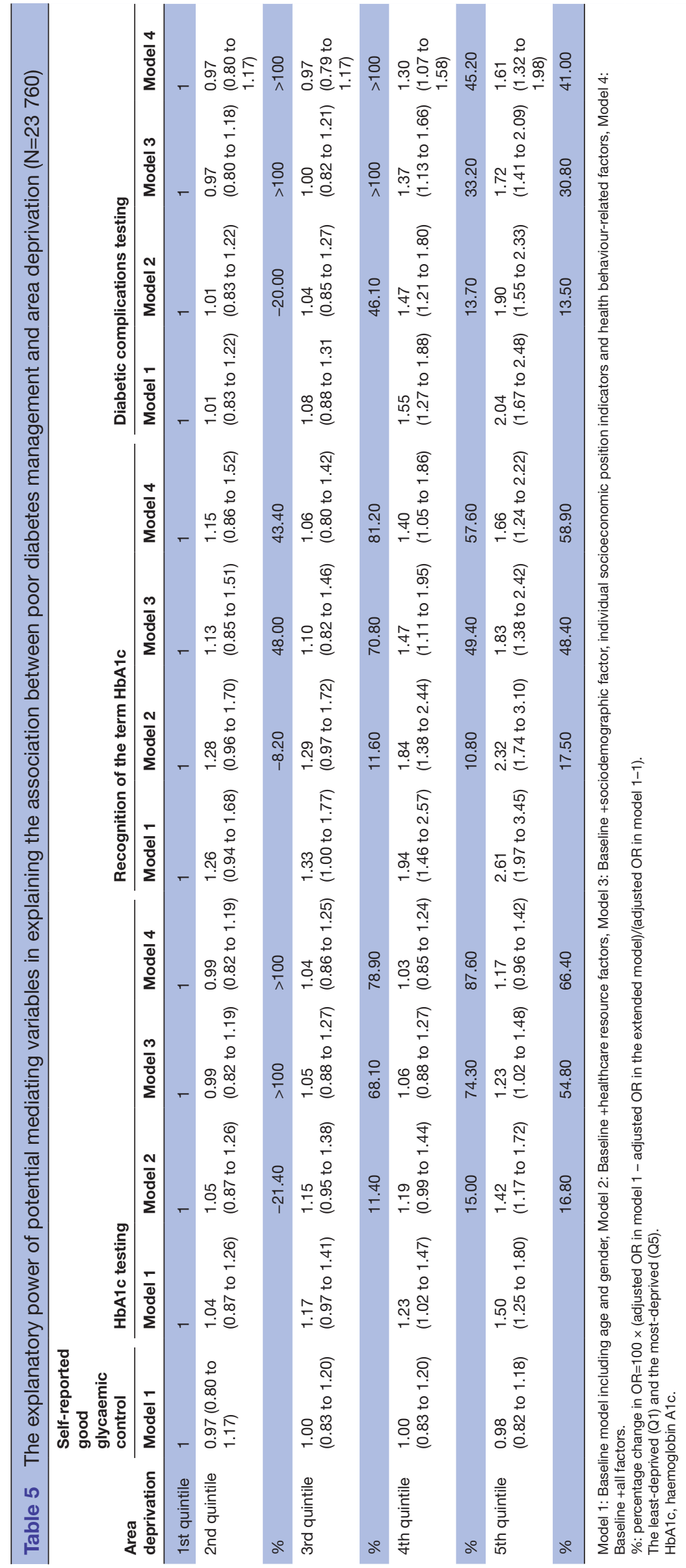


to administrative districts, a previous study calculated the geographic distances to healthcare institutions considering people's daily activities. ${ }^{71}$ However, we selected 250 districts as analysis units so representative data were calculated on an administrative district basis, allowing us to identify the need for regional units to resolve health inequalities. Third, we could not differentiate between type 1 and type 2 diabetes, because the KCHS questionnaire does not distinguish between them. However, since the prevalence of type 1 diabetes in the population aged 30 years or older is very low compared with type 2 diabetes, ${ }^{72}$ it is thought that it may not have had a significant impact on the results of our study. Fourth, due to the limitations of the data, we could not consider the level of exercise intensity, which may be important to measure regular physical activity. Also, because KCHS lacks clinical data on blood glucose, we analysed based on the self-reported data on good glycaemic control. Fifth, the percentage excess risk explained was used to evaluate the role of mediating variables. However, this method could lead to underestimating the mediating effect compared with the recently proposed method, ${ }^{73}$ so the results should be interpreted in consideration of this point. Sixth, the data KCHS used in this study presented weighting values to make the sample survey representative. However, we could not use the weights in the multilevel analysis, SAS GLIMMIX, in the process of analysing the inequality of diabetes management by considering individual-level and area-level variables. The results should be interpreted with this in consideration. Despite these limitations, our findings indicate that the distribution of healthcare resources is an important factor in explaining diabetes management inequalities resulting from area deprivation. This suggests a need to reduce area-based inequalities in diabetes management through the appropriate allocation of healthcare resources.

\section{Conclusions}

People with diabetes living in the most deprived areas were more likely to have poor diabetes management. The risk of poor diabetes management could be explained by the distribution of regional healthcare resources. Deprived areas may have decreased access to glycaemic control healthcare services, leading to poorer diabetes management. Our study suggests that the appropriate allocation of healthcare resources could reduce inequalities in diabetes management.

Contributors $\mathrm{RH}$ carried out the statistical analysis, interpreted the data, and wrote the manuscript. KJ-C supervised the statistical design and data interpretation. KJ-C is the guarantor of this work. Both authors read and approved the final manuscript.

Funding This study was supported by the Korean Society for Preventive Medicine funded by a grant from the Korea Disease Control and Prevention Agency. Award/ grant number is not applicable.

Competing interests None declared.

Patient and public involvement Patients and/or the public were not involved in the design, or conduct, or reporting, or dissemination plans of this research.

Patient consent for publication Not applicable.

Ethics approval This study was approved by the Institutional Review Board of the Ewha Womans University School of Medicine, Seoul, Korea (SEUMC 2020-07-014).
Provenance and peer review Not commissioned; externally peer reviewed.

Data availability statement Data are available in a public, open access repository. Data are available on the website of Community Health Survey (https://chs.kdca.go. kr/chs/index.do) and Public Data Portal (https://www.data.go.kr/index.do)

Open access This is an open access article distributed in accordance with the Creative Commons Attribution Non Commercial (CC BY-NC 4.0) license, which permits others to distribute, remix, adapt, build upon this work non-commercially, and license their derivative works on different terms, provided the original work is properly cited, appropriate credit is given, any changes made indicated, and the use is non-commercial. See: http://creativecommons.org/licenses/by-nc/4.0/.

\section{ORCID iD}

Rangkyoung Ha http://orcid.org/0000-0001-8060-8494

\section{REFERENCES}

1 International Diabetes Federation. IDF diabetes atlas. 9th edn. Brussels, Belgium, 2019. https://www.diabetesatlas.org

2 World Health Organization. Global report on diabetes. Geneva, Switzerland, 2016. https://www.who.int/publications/i/item/ 9789241565257

3 Agency KDCaP. Trends in prevalence of diabetes among Korean adults aged 30 years and over, 2007-2018, 2019. Available: https:// nih.go.kr/board/board.es? $\mathrm{mid}=\mathrm{a} 20602010000 \&$ bid=0034\&list_no $=$ 365142\&act=view [Accessed 10 May 2021].

4 Korean Diabetes Association. Diabetes fact sheet in Korea 2020 2020. Available: https://www.diabetes.or.kr/pro/news/admin.php? mode=list\&category=A [Accessed 10 May 2021].

5 Tao X, Li J, Zhu X, et al. Association between socioeconomic status and metabolic control and diabetes complications: a cross-sectional nationwide study in Chinese adults with type 2 diabetes mellitus. Cardiovasc Diabetol 2016;15:1-10.

6 Brown AF, Gregg EW, Stevens MR, et al. Race, ethnicity, socioeconomic position, and quality of care for adults with diabetes enrolled in managed care: the translating research into action for diabetes (TRIAD) study. Diabetes Care 2005;28:2864-70.

7 Bachmann MO, Eachus J, Hopper CD, et al. Socio-economic inequalities in diabetes complications, control, attitudes and health service use: a cross-sectional study. Diabet Med 2003;20:921-9.

8 Bihan $\mathrm{H}$, Laurent S, Sass C, et al. Association among individual deprivation, glycemic control, and diabetes complications: the EPICES score. Diabetes Care 2005;28:2680-5.

9 Arday DR, Fleming BB, Keller DK, et al. Variation in diabetes care among states: do patient characteristics matter? Diabetes Care 2002;25:2230-7.

10 Laraia BA, Karter AJ, Warton EM, et al. Place matters: neighborhood deprivation and cardiometabolic risk factors in the diabetes study of Northern California (DISTANCE). Soc Sci Med 2012;74:1082-90.

11 Geraghty EM, Balsbaugh T, Nuovo J, et al. Using geographic information systems (GIS) to assess outcome disparities in patients with type 2 diabetes and hyperlipidemia. J Am Board Fam Med 2010;23:88-96.

12 Bebb C, Kendrick D, Stewart J, et al. Inequalities in glycaemic control in patients with type 2 diabetes in primary care. Diabet Med 2005;22:1364-71.

13 Kim W, Choy YS, Lee SA, et al. Implementation of the Chronic Disease Care System and its association with health care costs and continuity of care in Korean adults with type 2 diabetes mellitus. BMC Health Serv Res 2018;18:1-7.

14 Levesque J-F, Harris MF, Russell G. Patient-Centred access to health care: conceptualising access at the interface of health systems and populations. Int J Equity Health 2013;12:18-19.

15 Salkever DS. Accessibility and the demand for preventive care. Soc Sci Med 1976;10:469-75.

16 Frenk J, White KL. The concept and measurement of accessibility. PAHO Scientific Publication, Pan American Health Organization, 1992: 842-55.

17 Kirby JB, Kaneda T. Neighborhood socioeconomic disadvantage and access to health care. J Health Soc Behav 2005;46:15-31.

18 Jin Y, Zhu W, Yuan B, et al. Impact of health workforce availability on health care seeking behavior of patients with diabetes mellitus in China. Int J Equity Health 2017;16:1-10.

19 Omrani-Khoo H, Lotfi F, Safari H, et al. Equity in distribution of health care resources; assessment of need and access, using three practical indicators. Iran J Public Health 2013;42:1299.

20 Policy Wiki. Moon Jae-in care, 2020. Available: https://www.korea. $\mathrm{kr} / \mathrm{special} /$ policyCurationView.do?newsld $=148863918$ [Accessed 25 May 2021]. 
21 Korea NAo. Major policy records in South Korea - Chapter 3 health policy, 2016. Available: https://archives.go.kr/next/news/ viewPublicationList.do?bg_no=360 [Accessed 25 May 2021]

22 Kim C-Y. Publicness in health and health care - From agents to health Regime- Seoul: Hanul 2019.

23 Lee Y. Regional distribution and characteristics of health care resources. J KRSA 2005;21:3-27.

$24 \mathrm{Kim}$ YJ, Jeon JY, Han SJ, et al. Effect of socio-economic status on the prevalence of diabetes. Yonsei Med J 2015;56:641.

25 Hwang J, Shon C. Relationship between socioeconomic status and type 2 diabetes: results from Korea National health and nutrition examination survey (KNHANES) 2010-2012. BMJ Open 2014;4:e005710

26 Min H, Chang J, Balkrishnan R. Sociodemographic risk factors of diabetes and hypertension prevalence in Republic of Korea. Int $J$ Hypertens 2010;2010:1-6.

27 Korea Disease Control and Prevention Agency. Data from: 2018 Korean community health survey. community health survey website, July 1, 2019. Available: https://chs.kdca.go.kr/chs/rdr/ rdrInfoProcessMain.do

$28 \mathrm{Kim}$ YT, Choi BY, Lee KO, et al. Overview of Korean community health survey. J Korean Med Assoc 2012;55:74-83.

29 Kang YW, Ko YS, Kim YJ, et al. Korea community health survey data profiles. Osong Public Health Res Perspect 2015;6:211-7.

$30 \mathrm{Cho} \mathrm{EH}$, Shin D, Cho KH, et al. Prevalences and management of diabetes and pre-diabetes among Korean Teenagers and Young Adults: results from the Korea National Health and Nutrition Examination Survey 2005-2014. J Korean Med Sci 2017;32:1984-90.

31 Health Insurance Review \& Assessment Service. Data from: status of the establishment of medical institutions. public data portal Repository, October 27, 2021. Available: https://www.data.go.kr/ data/15051057/fileData.do

32 Korean Diabetes Association. Clinical practice guidelines for diabetes 2021.

33 Jarman B, Townsend P, Carstairs V. Deprivation indices. BMJ 1991;303:523.

34 Choi J, Kim D, Lee J-H. Relative regional deprivation in Korea: current state and trends. Health and Welfare Policy Forum 2019;272:54-69.

$35 \mathrm{Ha} \mathrm{R}, \mathrm{Kim} \mathrm{D}$, Choi J, et al. A national pilot program for chronic diseases and health inequalities in South Korea. BMC Public Health 2021;21:1-10.

36 Cencus. Available: http://www.census.go.kr/cui/cuiKorView.do?q menu=1\&q_sub=3 [Accessed 20 Sep 2021].

37 Ahmed AT, Karter AJ, Liu J. Alcohol consumption is inversely associated with adherence to diabetes self-care behaviours. Diabet Med 2006;23:795-802.

38 Welfare MoHa, Center NC. Guidelines for the practices of physical activities for the prevention of cancer 2017

39 OECD Indicators. Health at a glance 2019.

40 Smiley W, Leighton E, Guo Z, eds. An intermediate guide to estimating multilevel models for categorical data using $S A S \otimes P R O C$ GLIMMIX. Proceedings of the Southeast SAS User Group (SESUG) Conference, 2015

41 Kong KA, Khang Y-H, Cho H-J, et al. Neo-Marxian social class inequalities in self-rated health among the employed in South Korea: the role of material, behavioral, psychosocial, and workplace environmental factors. BMC Public Health 2017;17:1-12.

42 Mindell JS, Knott CS, Ng Fat LS, et al. Explanatory factors for health inequalities across different ethnic and gender groups: data from a national survey in England. J Epidemiol Community Health 2014;68:1133-44.

43 van Oort FVA, van Lenthe FJ, Mackenbach JP. Material, psychosocial, and behavioural factors in the explanation of educational inequalities in mortality in the Netherlands. J Epidemiol Community Health 2005;59:214-20.

44 Khang Y-H, Kim HR. Explaining socioeconomic inequality in mortality among South Koreans: an examination of multiple pathways in a nationally representative longitudinal study. Int $J$ Epidemiol 2005;34:630-7.

45 Stronks K, Van De Mheen HD, Looman CWN, et al. Behavioural and structural factors in the explanation of socio-economic inequalities in health: an empirical analysis. Sociol Health \& IIIness 1996;18:653-74.

46 Lee J, Kim M-H. The effect of employment transitions on physical health among the elderly in South Korea: a longitudinal analysis of the Korean retirement and income study. Soc Sci Med 2017:181:122-30.

47 Whyte MB, Hinton W, McGovern A, et al. Disparities in glycaemic control, monitoring, and treatment of type 2 diabetes in England: a retrospective cohort analysis. PLoS Med 2019;16:e1002942.
48 Hippisley-Cox J, O'Hanlon S, Coupland C. Association of deprivation, ethnicity, and sex with quality indicators for diabetes: population based survey of 53,000 patients in primary care. $B M J$ 2004;329:1267-9.

49 James GD, Baker P, Badrick E, et al. Ethnic and social disparity in glycaemic control in type 2 diabetes; cohort study in general practice 2004-9. J R Soc Med 2012;105:300-8.

50 Collier A, Ghosh S, Hair M, et al. Impact of socioeconomic status and gender on glycaemic control, cardiovascular risk factors and diabetes complications in type 1 and 2 diabetes: a population based analysis from a Scottish region. Diabetes Metab 2015:41:145-51.

51 Andersen RM, Davidson PL, Baumeister SE. Improving access to care in America. Changing the US health care system: key issues in health services policy and management. 3rd edn. San Francisco: Jossey-Bass, 2007: 3-31.

52 Andersen RM, Yu H, Wyn R, et al. Access to medical care for lowincome persons: how do communities make a difference? Med Care Res Rev 2002;59:384-411.

53 Kirby JB. Poor people, poor places and access to health care in the United States. Social Forces 2008;87:325-55.

54 Engelman KK, Hawley DB, Gazaway R, et al. Impact of geographic barriers on the utilization of mammograms by older rural women. $J$ Am Geriatr Soc 2002;50:62-8.

55 Kliner M, Fell G, Gibbons C, et al. Diabetic retinopathy equity profile in a multi-ethnic, deprived population in Northern England. Eye 2012;26:671-7.

56 Choi D-W, Lee SA, Lee DW, et al. Effect of socioeconomic deprivation on outcomes of diabetes complications in patients with type 2 diabetes mellitus: a nationwide population-based cohort study of South Korea. BMJ Open Diabetes Res Care 2020;8:e000729.

57 Tudor Hart J. The inverse care law. Lancet 1971;297:405-12.

58 Jeon B-Y, Choi S-M, Kim C-Y. Socioeconomic equity in regional distribution of health care resources in Korea. Korean J Health Policy Admin 2012;22:85-108.

59 Lee Y-J. An study on the inepuality of health care resources distribution affected by regional characteristics. J Crit Soc Welfare 2005;21:49-78

60 Shin $\mathrm{H}-\mathrm{S}$, Lee S-H. Factors affecting spatial distance to outpatient health services. Korean J Health Policy Admin 2011;21:23-43.

61 Macintyre S, Ellaway A. Ecological approaches: rediscovering the role of the physical and social environment. Soc Epidemiol 2000;9:332-48

62 Bijlsma-Rutte A, Rutters F, Elders PJM, et al. Socio-economic status and $\mathrm{HbA}_{1 \mathrm{c}}$ in type 2 diabetes: A systematic review and meta-analysis. Diabetes Metab Res Rev 2018;34:e3008.

63 Choi J-H, Na B-J, Chun S-A. Factors related to fundus examination in diabetes mellitus patients. Korean J Health Policy Admin 2010;20:125-36.

64 An S, Yu J. Factors influencing fundus examination in patients with diabetes. J Korean Public Health Nurs 2018;32:44-55.

65 Bains SS, Egede LE. Associations between health literacy, diabetes knowledge, self-care behaviors, and glycemic control in a low income population with type 2 diabetes. Diabetes Technol Ther 2011;13:335-41.

66 Nutbeam D. Health promotion glossary. Health promotion international. Geneva: Oxford University Press, 1998.

67 Knighton AJ, Brunisholz KD, Savitz ST. Detecting risk of low health literacy in disadvantaged populations using area-based measures. EGEMS 2017:5:7.

68 Savitz ST, Bailey SC, Dusetzina SB, et al. Treatment selection and medication adherence for stable angina: the role of area-based health literacy. J Eval Clin Pract 2020;26:1711-21.

69 Sentell T, Zhang W, Davis J, et al. The influence of community and individual health literacy on self-reported health status. J Gen Intern Med 2014;29:298-304.

70 Paasche-Orlow MK, Wolf MS. The causal pathways linking health literacy to health outcomes. Am J Health Behav 2007;31 Suppl 1:S19-26.

71 Lee S. Potential spatial access to health care for diabetic and hypertensive outpatients [Doctoral dissertation]: The Graduate School of Public Health Seoul National University, 2014.

72 Bullard KM, Cowie CC, Lessem SE, et al. Prevalence of diagnosed diabetes in adults by diabetes type-United States, 2016. MMWR Morb Mortal Wkly Rep 2018;67:359.

73 Karlson KB, Holm A, Breen R. Comparing regression coefficients between same-sample nested models using logit and probit. Sociol Methodol 2012;42:286-313. 